\title{
High school students' perception of bullying as a phenomenon of group action
}

\author{
Elena Harlanova ${ }^{1, *}$, Nadezhda Sivrikova ${ }^{1}$, Inna S. Popova ${ }^{2}$, and Ekaterina A. Lapaeva ${ }^{3}$ \\ ${ }^{1}$ SUSHPU, Department of Social Work, Pedagogy and Psychology, Chelyabinsk, Russia \\ ${ }^{2}$ Youth center «Cheryomushki», Lazyrniy village, Russia \\ ${ }^{3} \mathrm{GBU}$ «Youth Resource Center», Chelyabinsk, Russia
}

\begin{abstract}
Bullying is a dangerous phenomenon that affects many modern students around the world. Bullying destructively affects a person regardless of the role (aggressor, observer, victim) and, despite measures to overcome, is present at school. Bullying (from the point of view of the contextual approach) is a social-group phenomenon that accompanies the development of a group with an unconstructive deformation of relationships in it. We conducted a research that reveals how Russian students are prone to bullying, how (taking into account gender and experience of it) are aware of its causes, who can stop bullying and whom they are ready to turn for help to if they become observers or victims of bullying. The results of the study showed that $46.8 \%$ of students felt oppressed during the school year (2018-2019). Students realize that the school class can stop bullying, but in a bullying situation they turn to parents, teachers, less to friends, do not mention the school class.
\end{abstract}

\section{Introduction}

Bullying studies have expanded their geography over the past decade. So in addition to the traditionally North American (USA [1], Canada [2] and the European space (Italy [3], Spain [4], Sweden [5], Portugal [6], etc.), they extend to Asia [7-9], Arab states [10], South Africa [11], South America [12] and reveal both the prevalence of this phenomenon and the features of its manifestation in different countries. The research work focused on bullying in Russia have been intensified [13-15].

The research results show an increase in observed bullying [16], despite the established negative impact of bullying on all its participants (aggressors, victims, and partly observers), namely: decreased emotional intelligence [17], academic performance and wellbeing [18], manifestation of antisocial behavior and aggressive conflict resolution strategies [19], increasing stress levels, various emotional and behavioral problems [20]. Studies show insignificant differences in the negative impact of bullying and cyberbullying on internalizing personality problems [21], while the consequences of victimization persist until mid-life and affect mental health, physical and socio-economic results [22].

\footnotetext{
${ }^{*}$ Corresponding author: harlanovaem@cspu.ru
} 
Sharing the opinion of several authors on the prospects of bullying studies from the perspective of the contextual approach (studying the environment, microclimate of the group, system processes in the community) [23], studying the context in the key of the sociocultural approach [24], turning to the individual contextual approach (studying the influence of social contexts on weakening or aggravation of individual characteristics of bullying participants) [25], we will focus on teenagers perceiving bullying as a phenomenon of group action [15], maintaining and protecting their social position [5], peer status [14].

From this position, it is important to take into account the actions of various factors affecting bullying [4], [26] both risk factors and protective factors [27]. Researchers consider two groups of factors 1) intrapersonal: teenage loneliness [28], mechanisms of moral disengagement [29], self-esteem [30], empathy, self-efficacy [31], the meaning that students give to bullying [32], etc. 2) contextual: school climate [18], friendship, social environment (group and social norms) [31], etc.

Teenagers can choose the position of aggressors, since it has advantages in obtaining and maintaining their status in the classroom, victims are more rejected and excluded, and hooligans have a better emotional and social position [4], compared with aggression, victimization has a greater effect on the appearance of stress, internalization and externalization of emotional and behavioral problems [20], but at the same time, aggressive behavior will have negative consequences, it is associated with school failures [6].

The development of the school climate in which students act aggressively or not, feel safe or not depends on the development of relationships between group members, between students and teachers, teachers and the administration [18]. The use of moral demarcation, deposition and distribution of responsibility for bullying depends on group dynamics [29].

Therefore, it is important to understand not only how susceptible teenagers are to bullying and its forms, but also how they understand its causes, whether they are ready to interact with others to counter it, how they perceive relationships within the class and what role they attach to the group (school class) in this process.

\section{Purpose of the Study}

The purpose of the study is to identify what place in the ideas of Russian teenagers about bullying is occupied by a group (school class).

Research questions: 1) what is the prevalence of bullying and its forms; 2) what is the idea of adolescents about bullying (its reasons, who can stop bullying, to whom they are ready to turn for help); 3) whether there is a difference in the perception of bullying, taking into account gender and experience of intimidation; 4) whether the experience of bullying and the assessment by the subject of relations in the class, as well as the violent actions of other subjects, are related.

\section{Research Methods}

As part of a study conducted in two regions of Russia (Krasnoyarsk Territory and Chelyabinsk Region), 458 students from grades 7 to 10 (13 to 16 years old) were surveyed. Of these, students in grade $7-188$ people, grade $8-79$ people, grade 9 - 165 people, grade 10 - 26 people. Girls - 238 people (52\%), boys - 220 people (48\%).

For mathematical data processing we used the Cramer V-test.

\section{Results}


Data on adolescent bullying showed that during the school year (2018-2019), 52.4\% of adolescents did not experience it, $46.8 \%$ of those surveyed experienced it, $12.7 \%$ of them experienced physical bullying, and verbal $22.9 \%$, social $-6.9 \%$, on the Internet $-4.1 \%$. Three students, answering the "other" question, noted that they were intimidated by teachers.

The schoolchildren called the causes of oppression: "appearance" $-27.7 \%$, "grades" $25.1 \%$ "occupations and hobbies, because they are not like the majority" - 20\%, "gender" $3.7 \%$, "economic status of the family"- 3.3\%, "limited health opportunities"- $3.2 \%$, "religion"- $2 \%$, "culture"- $1.7 \%$. It was found that there are significant relationships between gender and perceptions of the causes of bullying. Girls more often note: appearance $(\mathrm{V}=0.195 ; \mathrm{p}=0.001)$, gender $(\mathrm{V}=0.096 ; \mathrm{p}=0.039)$. Boys more often indicate: culture $(\mathrm{V}=0.072 ; \mathrm{p}=0.039)$, economical status of the family $(\mathrm{V}=0.093 ; \mathrm{p}=$ 0.046).

Using the "other" option, individual students noted that the causes of bulling were not in them, but in the people around them: "because there are bad people at school," "there are classmates who bring me along", "because of the environment in class", "student relations", "there is a girl who makes fun of me", "teachers crush me", as well as those related to the school's position "because I am a newcomer".

Teenagers indicated that subjects capable of stopping bullying are: teachers $-32.5 \%$, school psychologist or social teacher - 30.0\%, directors - $29.3 \%$, authorities (juvenile commission, education department) $-27.7 \%$, self - $24.2 \%$, class $-21.2 \%$, parents $-19.0 \%$, children's ombudsman $-16.6 \%$, friend $-7.6 \%$, no one can $-4.5 \%$. Girls more often mention teachers $-38.2 \%(26.4 \%$ of boys $)(\mathrm{V}=0.127 ; \mathrm{p}=0.007)$, more often they use the other option $(\mathrm{V}=0.138 ; \mathrm{p}=0.003)$.

$37.6 \%$ of respondents are ready to talk with adults about bullying, $37.6 \%$ of respondents are doubt that can do this, $24.9 \%$ of respondents will not contact adults. Girls are more inclined to communicate with adults, of which $45.4 \%$ answered "yes" and only $29.1 \%$ of boys $(\mathrm{V}=0.175 ; \mathrm{p}=0.001)$. No significant differences were found between those with experience of oppression and those without respondents on this issue.

In the case of a bullying situation, students will turn to: parents $-26.6 \%$, teachers and class teacher $-24.2 \%$, police $-10.3 \%$, friends $-8.7 \%$, school administrations (principal and his deputies) $-7.6 \%$, psychologist $-4.4 \%$, self $-4.4 \%$, helpline - $2 \%$, authorities $-1.3 \%$, children's ombudsman - $1.3 \%$, social educator - $0.7 \%$. $8.5 \%$ of schoolchildren answered that they did not know who they would turn to, $6.3 \%$ of teenagers would not turn to anyone. Girls are more likely than boys to turn to: $34.5 \%$ (18.2\% of boys) to their parents (V = $0.184 ; \mathrm{p}=0.0001)$; teachers $23.9 \%(9.1 \%$ of boys $)(\mathrm{V}=0.199 ; \mathrm{p}=0.0001)$, class teacher $10.5 \%(4.5 \%$ of boys $)(\mathrm{V}=0.112 ; \mathrm{p}=0.016)$, are configured to use the phone trust $3.4 \%$ $(0.5$ young men $)(\mathrm{V}=0.105 ; \mathrm{p}=0.025)$, children's ombudsman $2.1 \%(0 \%$ young men $)(\mathrm{V}=$ $0.101 ; \mathrm{p}=0.031)$. Boys more often than girls are more self-oriented $6.8 \%(2.1 \%$ girls $)(\mathrm{V}=$ $0.115 ; \mathrm{p}=0.014)$. However, no significant differences were found between the responses of adolescents with experience of bulling and no such experience.

Pupils with experience of bullying are less often called the friendly class $(\mathrm{V}=0.151 ; \mathrm{p}$ $=0.033$ ), almost three times less likely to say that "the class spends a lot of time together outside the school" $(\mathrm{V}=0.151 ; \mathrm{p}=0.033)$, they often feel uncomfortable at school, $87.2 \%$ compared with those who did not experience bullying in the current 2018-2019 school year, $49.6 \%$ (p 0.0001).

It was found that between the experience of bullying and attitudes towards the subject of violence, there are significant relationships. To the question "When do you see news that at some school a student used violence with weapons against classmates and teachers, what do you think?" The most common answer was "He/she did it because he/she has mental health problems" (69.0\% of students); "He/she did so because he/she was a victim of bullying" - 
40.1\%; "Got into a hopeless situation and there was no person near he/she could turn for help" - 21.4\%; "Saw violence on TV or in computer games" - 19.6\%.

Schoolchildren experiencing bullying more often than other schoolchildren say that "he/she did this because was bullied at school" $48.2 \%$ (36.7\% other schoolchildren) (V = $0.116 ; \mathrm{p}=0.013)$ and "saw scenes of violence by Media" $26.1 \%(13.8 \%$ other respondents $)$ $(\mathrm{V}=0.156 ; \mathrm{p}=0.001)$ and less often "because he/she has psychological deviations" $64.7 \%$ (75.4\% other respondents) $(\mathrm{V}=0.117 ; \mathrm{p}=0.012)$. Moreover, girls more often than boys choose the answer "did it because he/she had no one to ask for help" $26.5 \%$ of girls $(16.4 \%$ of boys) $(\mathrm{V}=0.123 ; \mathrm{p}=0.009)$.

\section{Discussion}

According to our data, $46.8 \%$ of respondents are covered by bullying, this is less than in the study [13], where coverage is about $57 \%$, but correspond to the data obtained in the USA [1] and Spain $46 \%$ [33].

There were no significant differences in the coverage of bullying and its forms between girls and boys as in the study [4]. Among the forms of bullying, cyberbullying is less common [3].

Adolescents mainly attribute the causes of bullying to the characteristics of the victim, which is comparable with studies that emphasize that the main mechanism of moral separation in bullying is the dehumanization of the victim and the victim's accusations, i.e. adolescents tend to attribute the guilt of harmful behavior to the victims themselves [29]. Adolescents who survived the experience of oppression often use circumstantial attribution when explaining the behavior of subjects of mass violence than other participants.

Most teenagers are not inclined to talk about bullying with adults $(62.8 \%)$, which is comparable with the data for Greece [34] where no more than $28 \%$ of secondary school students report bullying to teachers and parents.

At the same time, Russian adolescents most often call teachers, class teachers, a school psychologist, and the school administration as subjects who can stop bullying, but less often mention them as subjects they themselves are willing to address in a bullying situation. We believe that this is the result of existing relationships and traditions. In particular, the gap between generations of schoolchildren and teachers, noted by a number of authors, can explain the found attitudes [35].

We agree with the position of B. Kutsyurub, D.A. Klinger, A. Hussein [18] that cases of bullying in schools are the result of unhealthy relationships that can be influenced by the administration, together with the staff, by developing trusting relationships in schools, empowering teachers and working together to improve students' attitudes with peers and adults.

Teenagers are less likely to note that parents can influence the solution to the problem of bullying, but are more likely to contact them in a bullying situation. This requires the willingness of parents to assist in interacting with school staff and updates parental education programs [36].

Russian teenagers (with a few exceptions) are not inclined to turn to a psychologist because of the bullying situation unlike foreign teenagers [20].

The school class was noted by adolescents as a collective subject of baiting, but the survey participants did not mention it among those whom they would contact in a bullying situation. Probably adolescents do not have accessible forms of such influence, which is a consequence of prevailing practices of perception and resolution of conflicts. Our study did not reveal a connection between gender and the possibility of resorting to group support, as in the study [29].

The attitude to the class of students with experience of oppression differs from other respondents in a less positive assessment. Apparently, the very positive perception of 
relationships in the group, as shown by a study by N. Moyano, E. Allon, H.L. Antananzas, Y. Kano [33], does not allow to predict bullying, in contrast to the perception of negative relationships. The authors emphasized that social integration, awareness of conflicts, and the number of friends act as protective factors.

Therefore, it is necessary not only to develop positive relations in the classroom but to form an experience of constructive resolution of emerging conflicts (eliminating discrimination, forceful solution, expanding the practice of cooperation), which is feasible with the direct participation of employees of educational organizations.

\section{Conclusion}

An analysis of the prevalence of bullying among adolescents showed that about half of the students participating in the study were intimidated. Adolescents associate the causes of this phenomenon with the characteristics of the victim. There is a contradiction between the ideas about who can stop bullying and those to whom adolescents are ready to turn for help: $21.2 \%$ of the adolescent indicated that the class can help in solving this problem, but they themselves will turn to adults in this situation.

Teenage perceptions of bullying are related to gender and experience of it. Young men in a situation of oppression often rely on themselves, and girls - on adults. Those who were less likely to oppress their peers give positive ratings to the school class, and more often use circumstantial attribution to justify the actions of the aggressor.

The results of the study are of interest to professionals involved in the prevention of bullying at school. In particular, they indicate that for the prevention of bullying, pedagogical guidance on the development of group relations in the classroom is necessary.

This study was conducted as part of a project to combat bullying and cyberbullying and hostile language Agra.NET, supported by the Presidential Grants Fund.

\section{References}

1. E. M. Selkie, J. L. Fales, M. A. Moreno, Journal of Adolescent Health, 58(2), 125$133(2016)$

2. S. Salmon, S. Turner, T. Taillieu et al., Journal of Adolescence, 63, 29-40 (2018)

3. I. Zych, A.C. Baldry, D.P. Farrington, V. J. Llorent, Aggression and Violent Behavior, 83-97 (2018)

4. F. Cerezo, C. Ruiz-Esteban, C. S. Lacasa et al., Psicothema, 30(1), 59-65 (2018)

5. J. Strindberg, P. Horton, R. Thornberg, Research Papers in Education (2019)

6. M.J.D. Martins, A. Proenca, Revista Iberoamericana De Educacion, 80(2), 47-60 (2019)

7. H.C. Chan, D.S.W. Wong, Aggression and Violent Behavior, 23, 98-108 (2015)

8. A.L.C. Fung, Journal of Adolescent Health, 64(6), 65-72 (2019)

9. R. Sittichai, P.K. Smith, Aggression and Violent Behavior, 23, 22-35 (2015)

10. T. Elghossain, S. Bott, C. Akik et al., Journal of Adolescent Health, 64(1), 8-19 (2019)

11. D.T. Masilo, South African Journal of Education, 38 (2018)

12. D. Nieto, K. Bickmore, Revista Espanola De Educacion Comparada, 28, 109-134 (2016)

13. V.S. Sobkin, M. M. Smyslova, Social psychology and society, 5(2), 71-86 (2014)

14. V.A. Ivanyushina, V.V. Titkova, D.A. Alexandrov, Sociological journal, 22(1), 54-71 (2016) 
15. A.A. Gudzovskaya, A.M. Manukhina, A.A. Proskurina, Social phenomena, 1(7), 41-49 (2017)

16. I. Sanchez-Kaya, I. Garcia-Mine, K. Moreno, Journal of School Health, 87(6), 457-464 (2017)

17. N.G. Angel, Accion Psicologica, 16(1), 143-156 (2019)

18. B. Kutsyuruba, D.A. Klinger, A. Hussain, Review of Education, 3(2), 103-135 (2015)

19. M. Garaigordobil, Psychosocial Intervention-Intervencion Psicosocial, 26(1), 47$54(2017)$

20. M. Garaigordobil, J.M. Machimbarrena, Psychosocial Intervention, 28(2), 67-73 (2019)

21. G. Gini, N.A. Card, T. Pozzoli, Aggressive Behavior, 44(2), 185-198 (2018)

22. L. Arseneault, Journal of Child Psychology and Psychiatry, 59(4), 405-421 (2018)

23. A.A. Bochaver, K.D. Khlomov, Psychology. Journal of higher school of Economics, 10(3), 149-159 (2013)

24. R.E. Maunder, S. Crafter, Aggression and Violent Behavior, 38, 13-20 (2018)

25. E. Menesini, European Journal of Developmental Psychology, 16(3), 245-267 (2019)

26. T. Kretschmer, Adolescent Research Review, 1(4), 341-356 (2016)

27. I. Zych, R. Ortega-Ruiz, R. Del Rey, Aggression and Violent Behavior, 23, 1-21 (2015)

28. E.O. Acquah, P.Z. Topalli, M.L. Wilson et al., International Journal of Adolescence and Youth. 21(3), 320-331 (2016)

29. W.A. de Oliveira, S.C.S. Caravita, B. Colombo et al., Frontiers in Psychology, 10, (2019)

30. I. Tsaousis, Aggression and Violent Behavior, 31, 186-199 (2016)

31. F. Dominguez-Hernandez, L. Bonell, A. Martinez-Gonzalez, CyberpsychologyJournal of Psychosocial Research on Cyberspace, 12(4),1 (2018)

32. P. Esteves, Educacao \& Formacao, 4(11), 60-81 (2019)

33. N. Moyano, E. Ayllon, J.L. Antonanzas et al., Frontiers in Psychology, 10, (2019)

34. N. Mavroudis, P. Bournelli, Cogent Education, 3, (2016)

35. N.V. Sivrikova, E.M. Harlanova, E.A. Stolbova, Dilemas ContemporaneousEducation Politica y Valores, 108 (2019)

36. I. Lozano-Rodriguez, L. Valero-Aguayo, Revista De Psicologia Clinica Con Ninos Y Adolescentes, 4(2), 85-101 (2017) 